\title{
VENDA CASADA E A PIPOCA NO CINEMA: CONTROVÉRSIA JURÍDICA
}

\author{
Marcela Dieine Roque Ávila Siqueira; Sérgio Miranda Mendes; Fábio Ferreira Morong
}

Universidade do Oeste Paulista - UNOESTE, curso de Direito, Presidente Prudente, SP. E-mail: marcela.dra85@gmail.com

\section{RESUMO}

O instituto da venda casada, principalmente no que tange sua caracterização como prática abusiva em relação à venda de pipoca no cinema, fere um direito básico do consumidor, qual seja, a liberdade de escolha. Por outro lado, as empresas cinematográficas gozam da livre iniciativa, prevista na Constituição Federal. Assim, este trabalho objetiva realizar um estudo sobre a controvérsia jurídica que se fundou, baseado na livre iniciativa e na liberdade de escolha. Tendo como precedente o Recurso Especial no 744.602, hoje a matéria encontra-se no STF com a ADPF no398, estando aguardando um desfecho jurídico. O método aplicado foi o dedutivo legal, baseado na interpretação da legislação, jurisprudências e doutrinas. Conclui-se que a venda casada, que é considerada uma prática abusiva, restou evidenciada na conduta das empresas cinematográficas ao vedar a entrada dos consumidores em suas salas de projeção com alimentos e bebidas adquiridos alhures.

Palavras-chave: Consumidor. Venda Casada. Pipoca no cinema. Liberdade de escolha. Livre iniciativa.

\section{TIE-IN SALES AND POPCORN AT THE CINEMA: A LEGAL CONTROVERSY}

\begin{abstract}
The institute of tie-in sales, mainly regarding its characterization as abusive practice in relation to the sale of popcorn in cinema, it affects a basic right of the consumer: freedom of choice. On the other hand, cinematographic companies enjoy free iniciative, as established in the Federal Constitution. Thus, this work aims to conduct a study on the legal controversy since begun, based on free initiative and freedom of choice. Taking precedent is Special Appeal No. 744.602, today the subject is in the Supreme Court with ADPF no398, pending legal outcome. The method used was the legal deductive, based on legislative interpretation, jurisprudence and doctrine. It is concluded that the tie-in sale, which is considered an abusive practice, is still evident in the conduct of the cinematographic companies by prohibiting entry of clients in their projection rooms with food and beverages purchased elsewhere.
\end{abstract}

Keywords: Consumer. Tie-in Sale. Popcorn not Cinema. Freedom of choice. Free Initiative.

\section{INTRODUÇÃO}

Seria impossível cogitar a vida em sociedade sem consumo. O consumo está muito mais presente em nossas vidas do que podemos imaginar. Pois bem, a relação de consumo evoluiu significativamente a partir da Revolução Industrial, de modo que os produtos que anteriormente eram adquiridos pela simples troca entre os sujeitos, passaram a ser produzidos e comercializados em larga escala nos grandes centros urbanos. Igualmente as relações de consumo, a sociedade passou a modificar-se (CAVALIERI, 2014).

É inegável que a sociedade vem se desenvolvendo em uma velocidade tão instantânea como um piscar de olhos. Dia após dia, nos deparamos com algo novo no mercado. Contudo, 
independentemente desta evolução, as pessoas continuam praticando velhos hábitos quando se trata de entretenimento e lazer. É o caso dos cinemas, que datam mais um século de existência no Brasil. Assim como os outros ramos mercadológicos, este também vem utilizando a tecnologia em seu favor (MIRANDA, 2014).

Atualmente é possível assistir a filmes em 3D (terceira dimensão), com telas muito maiores e com som ambiente, sem deixar de mencionar o conforto das poltronas, temperatura agradável, entre outros. Mas quando se imagina uma sessão de cinema, o que logo paira sobre o pensamento? A resposta é sem dúvida alguma que cinema combina com pipoca. Contudo, o que não é sabido é que não são os consumidores obrigados a adquirir pipoca ou outras guloseimas vendidas nas dependências do estabelecimento cinematográfico, ou seja, podem comprar em outros estabelecimentos, ou até mesmo trazerem de casa.

Destarte, resta evidente que as empresas insistem em "forçar" a compra de tais produtos em suas dependências, o que segundo entendimento jurisprudencial e doutrinário, configura a venda casada, considerada uma prática abusiva à luz do Código de Defesa do Consumidor.

Logo, este trabalho objetiva estudar a divergência jurídica fundada na livre iniciativa e na liberdade de escolha e discutir seus reflexos nas esferas de responsabilização cível no âmbito de uma relação de consumo.

\section{METODOLOGIA}

O presente trabalho empregou pesquisas à legislação nacional, jurisprudências e doutrinas relevantes na matéria objeto de estudo. Foi empregado o método dedutivo para sistematizar os dados coletados a fim de cumprir o objetivo proposto.

\section{DA VENDA CASADA}

O instituto da venda casada consiste em uma prática abusiva disciplinada pelo Código de Defesa do Consumidor, onde dispõe em seu art. 39, que: “É vedado ao fornecedor de produtos ou serviços, dentre outras práticas abusivas: I - condicionar o fornecimento de produto ou de serviço ao fornecimento de outro produto ou serviço, bem como, sem justa causa, a limites quantitativos[...]." (BRASIL, 1990).

De acordo com a doutrina, "veda-se que o fornecedor ou prestador submeta um produto ou serviço a outro produto ou serviço, visando um efeito caroneiro ou oportunista para venda de novos bens." (TARTUCE, 2016, p. 470).

Nota-se que o legislador foi categórico, não restando dúvidas de que o consumidor não está obrigado a adquirir um produto ou serviço estipulado pelo fornecedor, para que possa obter o que de fato deseja. Lamentavelmente, mesmo sendo vedada pelo Código de Defesa do Consumidor, a venda casada ainda é muito praticada pelos fornecedores e empresários.

No que tange as sanções, aplicam-se as mesmas ao fornecedor que valer-se da prática abusiva, que vão desde administrativas à desconsideração da personalidade jurídica da empresa.

Por fim, vale ressaltar que o consumidor não pode ser constrangido a adquirir um produto ou serviço, condicionado a outro, ou à limitação quantitativa, podendo o fornecedor sofrer as sanções penais pertinentes.

\section{QUESTÕES POLÊMICAS ENVOLVENDO O SUPERIOR TRIBUNAL DE JUSTIÇA (STJ) X ARGUIÇÃO DE DESCUMPRIMENTO DE PRECEITO FUNDAMENTAL (ADPF) SUPERIOR TRIBUNAL DE JUSTIÇA (STJ)}

Restou evidente, como visto acima, que a questão ainda é controvertida nos tribunais. Complementando o contexto acima exposto, vejamos o que a ementa do STJ, em sede de Recurso Especial REsp 744.602, tratando um caso específico, dispôs em 2007: 
ADMINISTRATIVO. RECURSO ESPECIAL. APLICAÇÃO DE MULTA PECUNIÁRIA POR OFENSA AO CÓDIGO DE DEFESA DO CONSUMIDOR. OPERAÇÃO DENOMINADA 'VENDA CASADA' EM CINEMAS. CDC, ART. 39, I. VEDAÇÃO DO CONSUMO DE ALIMENTOS ADQUIRIDOS FORA DOS ESTABELECIMENTOS CINEMATOGRÁFICOS. 1. A intervenção do Estado na ordem econômica, fundada na livre iniciativa, deve observar os princípios do direito do consumidor, objeto de tutela constitucional fundamental especial (CF, arts. 170 e 5o, XXXII). 2. Nesse contexto, consagrou-se ao consumidor no seu ordenamento primeiro a saber: o Código de Defesa do Consumidor Brasileiro, dentre os seus direitos básicos "a educação e divulgação sobre o consumo adequado dos produtos e serviços, asseguradas a liberdade de escolha e a igualdade nas contratações" (art. 6o, II, do $C D C$ ). 3. A denominada 'venda casada', sob esse enfoque, tem como ratio essendi da vedação a proibição imposta ao fornecedor de, utilizando de sua superioridade econômica ou técnica, opor-se à liberdade de escolha do consumidor entre os produtos e serviços de qualidade satisfatório e preços competitivos. 4. Ao fornecedor de produtos ou serviços, consectariamente, não é lícito, dentre outras práticas abusivas, condicionar o fornecimento de produto ou de serviço ao fornecimento de outro produto ou serviço (art. 39 , I do $C D C$ ). 5 . A prática abusiva revela-se patente se a empresa cinematográfica permite a entrada de produtos adquiridos na suas dependências e interdita o adquirido alhures, engendrando por via oblíqua a cognominada 'venda casada', interdição inextensível ao estabelecimento cuja venda de produtos alimentícios constituiu a essência da sua atividade comercial como, verbi gratia, os bares e restaurantes. 6. O juiz, na aplicação da lei, deve aferir as finalidades da norma, por isso que, in casu, revela-se manifesta a prática abusiva. 7. A aferição do ferimento à regra do art. 170, da CF é interditada ao STJ, porquanto a sua competência cinge-se ao plano infraconstitucional. 8 . Inexiste ofensa ao art. 535 do CPC, quando o Tribunal de origem, embora sucintamente, pronuncia-se de forma clara e suficiente sobre a questão posta nos autos. Ademais, o magistrado não está obrigado a rebater, um a um, os argumentos trazidos pela parte, desde que os fundamentos utilizados tenham sido suficientes para embasar a decisão. 9. Recurso especial improvido.

(STJ - REsp: 744602 RJ 2005/0067467-0, Relator: Ministro LUIZ FUX, Data de Julgamento: 01/03/2007, T1 - PRIMEIRA TURMA, Data de Publicação: DJ 15/03/2007 p. 264REPDJ 22/03/2007 p. 286RT vol. 862 p. 109).

De acordo com o aludido acórdão do Superior Tribunal de Justiça, resta claro que foi caracterizada a venda casada pela empresa Cinemark Brasil S/A, praticada em desfavor de seus consumidores, quando vincula o serviço "exibição do filme", aos produtos (pipoca, refrigerante, café, entre outros), vendidos em seu estabelecimento. Na mencionada decisão o Superior Tribunal de Justiça entendeu que: "A intervenção do Estado na ordem econômica, fundada na livre iniciativa, deve observar os princípios do direito do consumidor, objeto de tutela constitucional fundamental especial (CF, arts. 170 e 5ㅇ, XXXII)" (BRASÍLIA, Superior Tribunal de Justiça, 2007).

Nesse sentido, a liberdade do agente econômico não seria absoluta, mas sim passível de controle, especialmente quando diante da implementação de uma prática abusiva. 
Segundo o Superior Tribunal de Justiça, o consumidor deve gozar de liberdade da escolha, que é um dos direitos básicos do consumidor, a saber: "a educação e divulgação sobre o consumo adequado dos produtos e serviços, asseguradas a liberdade de escolha e a igualdade nas contratações", (art. 6ㅇ, II, CDC).

A liberdade de escolha "assegura ao consumidor opção entre vários produtos e serviços com qualidade satisfatória e preços competitivos". (ALMEIDA, 2015, p. 51).

Nota-se que este preceito está sendo ferido quando a empresa usa do poder econômico ou técnico para obstá-lo.

Assim, o acórdão proferido pelo STJ, a respeito do REsp 744.602, reafirma a venda casada praticada pela empresa cinematográfica, que anteriormente já havia sido apontada pelo juízo de primeiro grau e tribunal superior.

Entende-se que esta prática abusiva (venda casada), que está sendo imposta pela empresa cinematográfica ao consumidor, fere um direito básico, que foi instituído pela ONU, em sua resolução no 39/248, e hoje compõe o art. 6ㅇ, II, do CDC, qual seja, a liberdade de escolha.

O consumidor tem o condão de escolher o local onde irá adquirir seus produtos alimentícios, ou até mesmo já trazê-los de sua residência, se assim o desejar, desde que estes se enquadrem ao ambiente frequentado.

Desta forma, o consumidor pode procurar a empresa cinematográfica apenas com a intenção de adquirir seu serviço principal, que é o entretenimento (apresentação do filme), pois é evidente que esse seu direito deve ser respeitado.

\section{DA ARGUIÇÃO DE DESCUMPRIMENTO DE PRECITO FUNDAMENTAL (ADPF)}

No mesmo prisma, a Associação Brasileira das Empresas Exibidoras Cinematográficas Operadoras de Multiplex (Abraplex), ajuizou Arguição de Descumprimento de Preceito Fundamental (ADPF 398), com pedido de liminar, no Supremo Tribunal Federal (STF), fundamentando-se por meio do Resp no 744.602, e outras decisões judiciais consolidadas em jurisprudência do STJ.

Na ADPF 398, que foi distribuída ao Ministro Edson Fachin, a Abraplex aponta como violados os preceitos fundamentais relativos à livre iniciativa (artigos 10, inciso IV; 5으, inciso XIII; 170, caput), à isonomia (artigo 5으, caput) e ao acesso à cultura (artigo 225, caput).

A mesma ainda não foi apreciada, porém apresenta o parecer do Procurador-Geral da República (PGR), Rodrigo Janot Monteiro de Barros (Supremo Tribunal Federal, 2016), que assim dispôs:

CONSTITUCIONAL. ARGUIÇÃO DE DESCUMPRIMENTO DE PRECEITO FUNDAMENTAL. ILEGITIMIDADE ATIVA. REPRESENTAÇÃO DE FRAÇÃO DE CATEGORIA ECONÔMICA. MÉRITO. JURISPRUDÊNCIA CONSOLIDADA DO SUPERIOR TRIBUNAL DE JUSTIÇA. PROIBIÇÃO DE ENTRADA DE CONSUMIDORES EM SALAS DE CINEMA COM BEBIDAS E ALIMENTOS DE OUTROS ESTABELECIMENTOS. PRÁTICA ABUSIVA E INFRAÇÃO ECONÔMICA. CARACTERIZAÇÃO DE "VENDA CASADA" POR VIA OBLÍQUA. AFRONTA À LIVRE CONCORRÊNCIA E À DEFESA DO CONSUMIDOR. 1. Não tem legitimidade para arguição de descumprimento de preceito fundamental entidade que represente mera fração da categoria econômica atingida pela norma. Precedentes. 2. É constitucional a intervenção do estado na ordem econômica para assegurar eficácia à defesa do consumidor, direito fundamental assegurado pelo art. 5ㅇ, XXXII, da Constituição da República, e à livre concorrência, princípio consagrado em seu art. 170, IV. O alcance das finalidades da ordem econômica exige 
ponderação e equilíbrio entre o valor da livre iniciativa com os demais princípios enumerados no art. 170 da CR, entre os quais se inclui a defesa do consumidor e a livre concorrência. 3. Não há alicerce constitucional nem infraconstitucional para vedar que clientes de salas de exibição cinematográfica nelas ingressem portanto bebidas e alimentos adquiridos em outros estabelecimentos. A vedação é abusiva, ao limitar, de forma injustificada, o poder de escolha da clientela, conforme já reconheceram o Superior Tribunal de Justiça, a Secretaria de Direito Econômico do Ministério da Justiça e a 3ạ Câmara de Coordenação e Revisão do Ministério Público Federal. 4. O setor empresarial da exibição em salas de cinema tem crescido de forma consistente nos últimos, e uma de suas maiores empresas cumpriu termo de compromisso de cessação de prática anticoncorrencial para se abster de impedir ingresso de alimentos de procedência externa, sem que isso tenha impedido seu crescimento. 5. Parecer pelo não conhecimento da arguição de descumprimento de preceito fundamental e, no mérito, por improcedência do pedido.

Preliminarmente, o Procurador Geral da República adverte sobre a vedação dos clientes adentrarem as salas de exibição cinematográficas portando alimentos adquiridos em outros estabelecimentos, reafirma se tratar de uma prática abusiva, conforme entendimento do STJ.

Analisando o princípio da livre concorrência, disposto no art. 170, IV, CF, nota-se que este possui limites que estão reunidos em outros valores constitucionalmente construídos, também dignos de proteção e promoção. É como no caso apresentado, onde de um lado há o princípio da livre concorrência, porém do outro, está o consumidor, parte vulnerável da relação de consumo.

Portanto, caso estes exercícios sejam abusivos, o ordenamento jurídico não os tolera, pois tutela o consumidor frente a sua vulnerabilidade.

Destarte, ainda que não apreciada pela Suprema Corte a ADPF 398, restou evidente que o parecer do Procurador Geral da República ratifica o entendimento de prática abusiva das empresas cinematográficas, o que está em consonância com os julgados anteriores do STJ e demais Tribunais Estaduais.

\section{CONCLUSÃO}

Com o presente artigo objetivou-se realizar um estudo sobre a divergência jurídica baseada na livre iniciativa e na liberdade de escolha, que se instalou diante da vedação realizada por algumas empresas cinematográficas de consumidores com produtos alimentícios que não foram adquiridos no próprio estabelecimento. Constatou-se que as decisões Superior Tribunal de Justiça e o parecer do ilustre Procurador Geral da República, que trazidas à baila, deixam óbvio a prática abusiva analisada em seus casos concretos.

Verificou-se também que a venda casada, que é considerada uma prática abusiva, ficou evidenciada na conduta das empresas cinematográficas. Apesar de ser aduzido que "não condiciona a venda de ingressos à aquisição das referidas mercadorias" e que estaria tendo seus lucros prejudicados (amparada pela livre inciativa), nota-se que a venda de produtos alimentícios não constitui sua atividade principal.

Observou-se ainda, que se por um lado existe a livre iniciativa, apresentada pelos fornecedores, de outro há a liberdade de escolha, que constitui um dos direitos básicos do consumidor. Ainda que ambos estejam disciplinadas pelo mesmo dispositivo (art. 170, CF), observa-se nas fundadas decisões que neste conflito de interesses nenhuma exploração poderá atingir os consumidores. 
Ademais, a discussão gira em torno não só dos princípios constitucionais, mas principalmente, na vedação do fornecedor imposta aos clientes adentrem as salas cinematográficas com os referidos alimentos, evidenciando a venda casada.

Portanto, ainda que existam alguns pontos divergentes em relação ao tema aqui estudado, é possível entender que, à luz das diretrizes básicas que constituem o Código de Defesa do Consumidor, que tem amparo também na Constituição Federal, a mencionada prática abusiva ainda sobrevive por todo o território nacional, o que de fato, gera uma preocupação que deve ser considerada pelo Poder Judiciário no momento de decidir e tentar pacificar o entendimento no sentido de fazer valer os direitos dos consumidores brasileiros.

\section{REFERÊNCIAS BIBLIOGRÁFICAS}

ALMEIDA, J. B. Manual de direito do consumidor. 6. ed. rev. e atual. São Paulo: Saraiva, 2015.

BRASIL. Arguição de descumprimento de preceito fundamental 398/DF. Parecer № 198.112/2016AsJConst/SAJ/PGR. Relator: Rodrigo Janot Monteiro de Barros. 30 ago. 2016.

BRASIL. Código de Defesa do Consumidor. 28. ed. São Paulo: Atlas, 2017.

BRASIL. Constituição (1988). Constituição da República Federativa do Brasil. 8. ed. São Paulo: Manoele, 2016.

BRASIL. Superior Tribunal de Justiça. (1. Turma). Administrativo. Recurso Especial. Aplicação de multa pecuniária por ofensa ao Código de Defesa do Consumidor. Operação denominada 'Venda Casada' em cinemas. CDC, art.39, I. Vedação do consumo de alimentos adquiridos fora dos estabelecimentos cinematográficos. Recurso Especial no 744.602 - Recorrente: Cinemark Brasil S/A - Recorrido: Estado do Rio de Janeiro. Relator: Ministro Luiz Fux. Brasília, 01 de março de 2007. Data de Publicação: DJ 15/03/2007 p. 264REPDJ 22/03/2007 p. 286RT vol. 862 p. 109. Disponível em: < https://stj.jusbrasil.com.br/jurisprudencia/8975371/recurso-especial-resp744602-rj-2005-0067467-0/inteiro-teor-14146158 >. Acesso em: 01 mai. 2017.

CAVALIERI FILHO, S. Programa de Direito do Consumidor. 4. ed. São Paulo: Atlas, 2014.

MIRANDA, P. L. A evolução do cinema. Jun. 2014. Disponível em: < http://www.cantodosclassicos.com/evolucao-do-cinema/>. Acesso em: 05 mai. 2017.

OLIVEIRA. A. M. E. M. de. et al. Normas e padrões para trabalhos acadêmicos e científicos da Unoeste. Coordenação: Regina Rita Liberati Silingovschi. - Presidente Prudente: Unoeste Universidade do Oeste Paulista, 2015. 78 f.: il.

TARTURCE, F.; NEVES, D. A. A. Manual de direito do consumidor: direito material e processual. 6. ed. rev., atual. e ampl. São Paulo: Método, 2017. 